\title{
UAV survey of a coastal cliff face - Selection of the best imaging angle
}

\author{
Jaud Marion 1, ", Letortu Pauline ${ }^{2}$, Thery Claire ${ }^{2}$, Grandjean Philippe ${ }^{3}$, Costa Stephane ${ }^{4}$, \\ Maquaire Olivier ${ }^{4}$, Davidson Robert ${ }^{4}$, Le Dantec Nicolas ${ }^{5,6}$
}

1 Univ Bretagne Occidentale, IUEM, CNRS, UMS 3113,Technopole Brest Iroise, Rue Dumont dUrville, F-29280 Plouzane, France.

2 Univ Bretagne Occidentale, IUEM, CNRS, UMR 6554,LETG,Technopole Brest Iroise, Rue Dumont dUrville, F-29280 Plouzane, France.

3 Univ Lyon 1, CNRS, UMR 5276, Lab Geol Lyon, 2 Rue Raphael Dubois,Batiment GEODE, F-69622

Villeurbanne, France.

${ }^{4}$ Normandie Univ, UNICAEN, CNRS, UMR 6554,LETG, F-14000 Caen, France.

${ }^{5}$ Cerema, Direct Eau Mer \& Fleuves, 134 Rue Beauvais, F-60280 Margny Les Compiegne, France.

6 Univ Bretagne Occidentale, IUEM, CNRS, UMR 6538,Geosci Ocean,Technopole Brest Iroise, Rue

Dumont dUrville, F-29280 Plouzane, France.

* Corresponding author : Marion Jaud, email address : marion.jaud@univ-brest.fr

\begin{abstract}
:
UAVs are relevant for monitoring cliff faces. In this study, several flights are performed with various imaging angles (nadir, 20 degrees, 30 degrees and 40 degrees off-nadir) to assess the impact of the imaging angle on the 3D cliff face reconstruction. Occlusions issues arising with sub-vertical cliffs make nadir surveys nearly irrelevant. The results obtained with 20 degrees, 30 degrees and 40 degrees offnadir imaging angles are satisfactory regarding texture restitution and accuracy with respectively $5.5 \mathrm{~cm}$, $5.9 \mathrm{~cm}$ and $4.9 \mathrm{~cm}$ of error, higher tilting angles yielding better reconstructions on sub-vertical or overhanging parts of the cliff. This article also investigates other parameters affecting tiepoint detection on the cliff face, as the effective overlap, the UAV-cliff face distance and the cliff face illumination. Guidelines are provided for UAV survey parameterization, aiming at capturing the whole cliff face with a good trade-off between distance to the cliff, flight height and spatial resolution of the photographs.
\end{abstract}

\section{Highlights}

Impact of the UAV camera tilting angle on the 3D cliff face reconstruction. Because of occlusions, irrelevance of nadir pointing camera for sub-vertical cliffs. Satisfying accuracy and texture for both $20^{\circ}$, $30^{\circ}$ and $40^{\circ}$ off-nadir imaging angles. Other parameters impacting tiepoint detection in the reconstruction process. 
Keywords : UAV, SfM photogrammetry, Tilted camera, Cliff face erosion, Coastal monitoring, Normandy 


\section{Introduction}

Coastal cliffs erosion is a significant hazard for the safety of people, buildings, utilities and infrastructure settled close to the coastline, especially given the a priori sudden and episodic nature of the erosion process in time and space. Risk management relies on regular diagnosis of the cliff face 
and assessment of the erosion rate. For very dynamic environments, like coastal chalk cliffs, frequent monitoring with high accuracy and high spatial resolution (no more than a few centimeters) is needed to detect rock falls and debris falls, quantify the eroded volumes and reveal the patterns of cliff failure, with the objective to better understand the processes triggering cliff failures (e.g.: $[1,2])$.

In situ direct measurements in these environments with sub-vertical relief are challenging [3]. Field surveys can be risky for the operators and data over sufficiently large portions of the coastline are needed to ensure spatial representativity. Remote sensing methods exist, either using photogrammetric techniques or laser scanner technologies, with different platforms operating at different ranges from the imaged target. Far-range remote sensing could be a solution in the future, but for now, satellite and aerial data do not enable to observe subtle changes because their resolution is not sufficient and because they generally capture only the cliff top [4]. Thus, considering their high spatial and temporal resolution, their low cost and their operational flexibility, near-range remote sensing methods (land-based or using UAVs) are increasingly used for the cliff face monitoring [4-8].

Among these near-range remote sensing methods, high-resolution measurements of the cliff face topography have been mainly performed with Terrestrial Laser Scanners (TLS) [4,7, 9-12]. TLS surveys yield accurate and dense 3D point clouds, nevertheless a TLS is an expensive equipment, allowing to cover only limited areas in the range of few hundreds of meters of coastline in a day of survey. Furthermore, because they are cumbersome to set-up in the field, they required easy access and are therefore only suitable to certain sites. As they are operated from the foreshore at the cliff foot, a sufficient distance from the cliff is needed to optimize the field of view. Depending on the study area, some parts of the cliff face may be invisible regardless of the choice of TLS station on the beach. As reported in [13], boat-based Mobile Laser Scanning (MLS) enables to quickly scan a long coastline (several kilometers of coastline scanned in one hour) with median point spacing up to 10 $\mathrm{cm}$, providing that meteorological and marine conditions are favorable and that it is possible to sail close to the shore. The use of TLS or MLS is therefore very dependent on coastal morphology, logistics and weather conditions.

Other near-range remote sensing methods offer interesting possibilities. Aerial LiDAR operated from Unmanned Aerial Vehicle (UAV) could become a potential alternative method in the future. At present time, the choice of on-boarded positioning sensors is very restricted because of limited payload constraints. As a consequence, direct georeferencing of UAV-borne LiDAR data is still poorly accurate (e.g. around $2.5 \mathrm{~m}$ according to [14]). Terrestrial photogrammetry can be an effective survey method for cliff face reconstruction, providing data at centimeter resolution, being easy to implement and low cost $[5,7,15]$. Nevertheless, easy and safe access to the area is necessary and some parts of the cliff may be invisible from a terrestrial point of view.

Here, we examine the capabilities of photogrammetric surveys of cliffs from UAVs. Unlike LiDAR, SfM photogrammetry does not require direct georeferencing. Also, unlike TLS or terrestrial photogrammetry, photogrammetric UAVs enable to quickly collect stereo-photographs over a large extent (about $600 \mathrm{~m}$ of coastline covered in $8 \mathrm{~min}$ ), with reduced effects of occlusion and without needing to access the foot of the cliff because the take-off and landing can be performed at the cliff top $[3,7,16-17]$. Furthermore, an advantage of photogrammetric UAV surveys is the possibility to change the viewing angle by tilting the camera in order to optimise the coverage of the cliff face and avoid occlusions. Some studies combine nadir and oblique $\left(60^{\circ}\right.$ off-nadir) imagery collected over 
several UAV flights $[3,18]$. In [16], photographs from three flight paths with various aiming direction (horizontal, $45^{\circ}$ oblique and vertical) are combined, mainly in order to limit distortions. In [6], images are taken with horizontal axis orientation and with the axis tilted $45^{\circ}$ downward. For forestry applications, UAV surveys are usually performed with a tilt angle of $45^{\circ}$ [19]. The viewing angle for oblique imagery is also a key issue for photogrammetric surveys in urban context [20-21]. The aim of the present study is to assess the impact of the imaging angle on 3D reconstruction of the cliff face and to identify the most relevant angle range. In this context, several flights have been performed with a different imaging angle for each flight. The angles have been chosen between nadir and $40^{\circ}$ off-nadir because it is the range of angles that can be achieved by agile satellites for high resolution imagery (lower than $1 \mathrm{~m}$ ), such as the Pleiades satellites that are likely to play be exploited for in coastal monitoring applications. Based on the present study, some guidelines are also provided to parametrize UAV surveys.

\section{Study area}

The area selected for this methodological study is a well-documented site, part of the DYNALIT observatory (French observatory of littoral zone dynamics), located along the English Channel, near the Cap d'Ailly in Varengeville-sur-Mer (NW of France, Normandy, Seine-Maritime) (Figure 1a). This portion of the coastline belongs to the northeastern part of the Parisian sedimentary Basin, where the Pays de Caux plateau abruptly ends in cliffs. This part of Seine-Maritime coastline is named the Alabaster Coast because coastal cliffs are white, made of chalk with flints of Upper Cretaceous [2223] (Figure 1b). At the top of the chalk strata lies a bed of clay and sandy sediment about 2-10 m thick, of Tertiary age (Paleogene) [24], which gives a brown color to the cliff (Figure 1b).

In this area, the studied cliff is about $40 \mathrm{~m}$ high, with a sub-vertical slope (from $75^{\circ}$ to $90^{\circ}$ ) (Figure 1c), and is cut by a dry valley, called Petit Ailly. At this location, the average tidal range is $8 \mathrm{~m}$ (macrotidal environment), uncovering at low tide a foreshore characterized by a wide shore platform slightly inclined toward the sea and a gravel barrier near the cliff foot contact. Thanks to the large tidal range, the wide platform and the dry valley offering an easy access to the foreshore, the entire cliff face can be observed from the foreshore (Figure 1b). According to the surveys of the cliff top evolution on vertical aerial photographs (1966-2008, [25]) and of the cliff face evolution by terrestrial laser scanning (2010-2017, [26]), the erosion value is of $0.36 \mathrm{~m} /$ year. Both layers (chalk and Tertiary strata) are prone to erosion, which explains the high annual retreat rate in this area, in comparison with average regional retreat rate (0.15 m/year from Cap d'Antifer to Le Tréport, 1966-2008 [25]). The modalities of erosion include rock falls (large-scale movements affecting all or part of the cliff face) and debris falls (very small blocks or flakes (up to a decimeter scale) falling from across the cliff face) [27]. Falls (from few $\mathrm{m}^{3}$ to hundreds of thousands $\mathrm{m}^{3}$ ) are ubiquitous across the cliff face. 

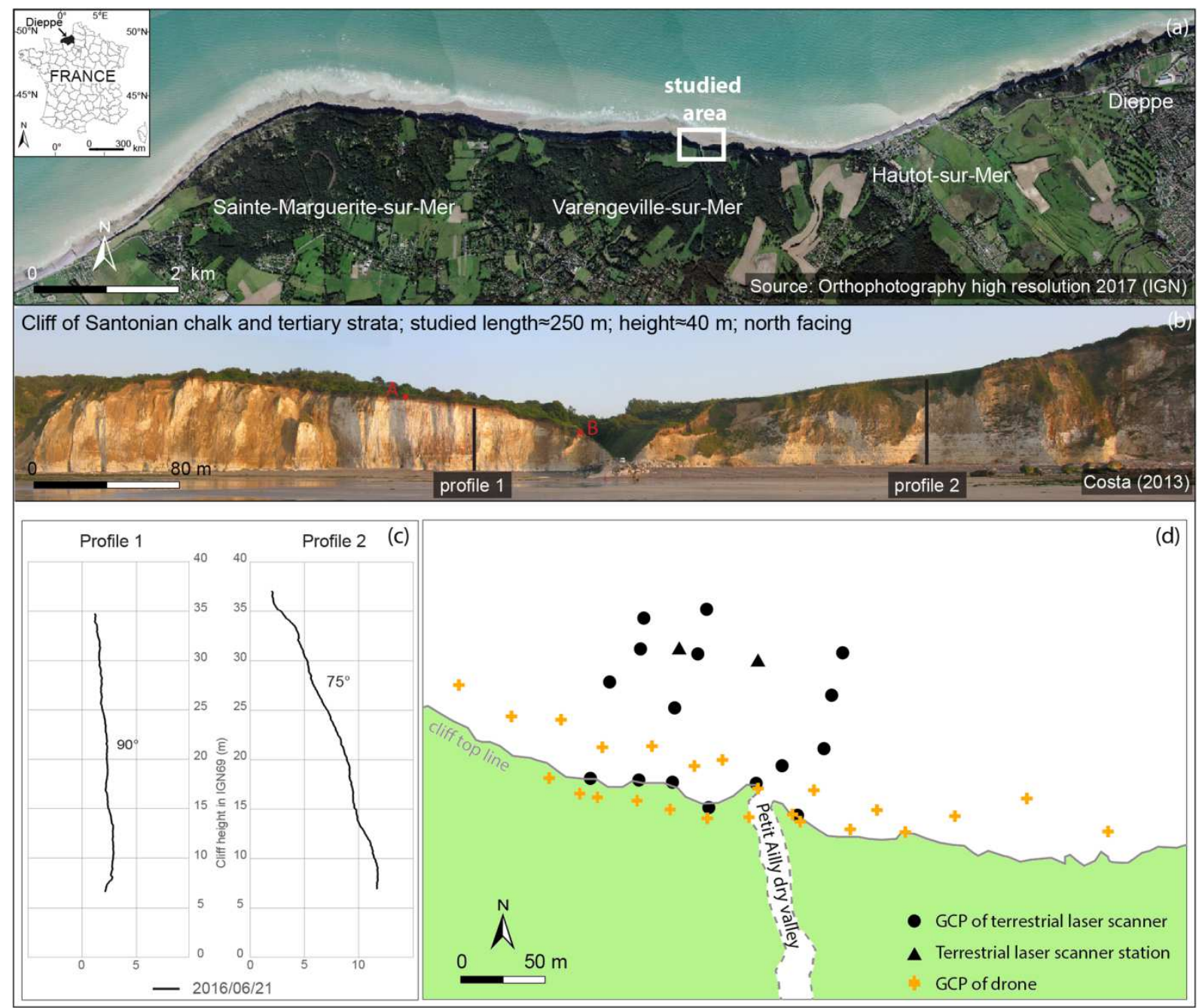

Figure 1: Location of the site (a), cliff face panorama (b), 2016/06/21 cliff face profiles (c), positions of GCPs for TLS and drone surveys (d)

\section{Material and methods}

The drone survey was realized using a DS6 electric hexacopter platform provided by DroneSys (Figure 2), thereafter named DRELIO. This multi-rotor UAV has a diameter of $0.8 \mathrm{~m}$, weighs less than $4 \mathrm{~kg}$ and can handle a payload of $1.6 \mathrm{~kg}$ with about $20 \mathrm{~min}$ of flight autonomy. DRELIO is equipped with a collapsible frame so it can be folded back for easy transportation and with a parachute rescue system to ensure a soft landing in case of technical problems. The flight control is run by DJI ${ }^{\circledR}$ iOSD $^{\circledR}$ software and the onboard flight control system is composed of a GPS and an autopilot.

A Nikon D700 digital reflex camera with a fixed focal length of $35 \mathrm{~mm}$, taking one $12 \mathrm{Mpix}$ photo (stored in JPEG fine format) every second in intervalometer mode, is mounted on a one-axis gimbal allowing forward-pointing of the camera. For data acquisition on the cliff face, various camera tilting angles (noted $\alpha$ ) are tested in the forward direction. As a flight performed in "automatic mode" would not allow to keep the camera oriented toward the cliff face. When the camera is tilted, the flight is therefore performed in "assisted mode", i.e. without programing the drone flight plan. In such configuration, the UAV trajectory is less smooth than in "automatic mode", the position of the drone being adjusted continuously during the flight by an operator monitoring the real-time stream of a low-resolution video camera data that shows the area being imaged. 


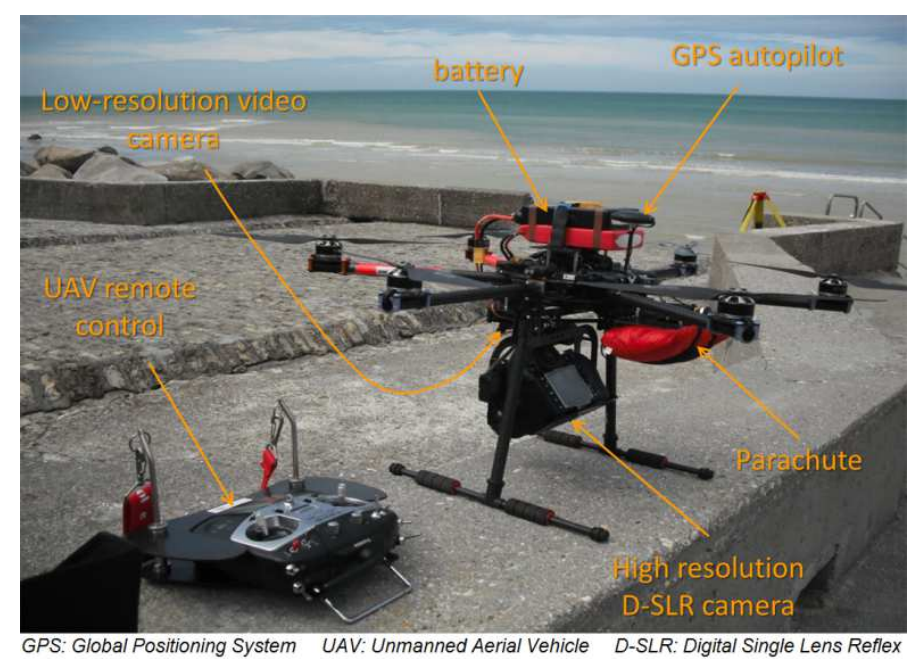

Figure 2 : DRELIO 10 hexacopter platform with tilted camera for photogrammetric surveys of the cliff face.

For this study, four flights were performed during low tide on June $21^{\text {st }}, 2016$, with various acquisition geometries:

- Flight 1: typical flight plan performed in "automatic mode" with nadir pointing camera;

- Flight 2: forward-pointing camera tilted at $\alpha=20^{\circ}$ off-nadir;

- Flight 3: forward-pointing camera tilted at $\alpha=30^{\circ}$ off-nadir;

- Flight 4: forward-pointing camera tilted at $\alpha=40^{\circ}$ off-nadir.

With a changing angle from one flight to another, the distance from the UAV to the cliff face has to be adapted to keep the cliff face in the imaging field-of-view. The impact of viewing angle is clearly visible on raw images. Figure 3 shows an example of the same portion of the cliff face as captured by a raw image from each flight.

a) Flight $1:$ nadir

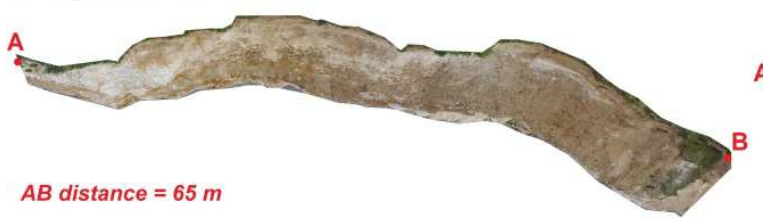

c) Flight 3: $30^{\circ}$ off-nadir

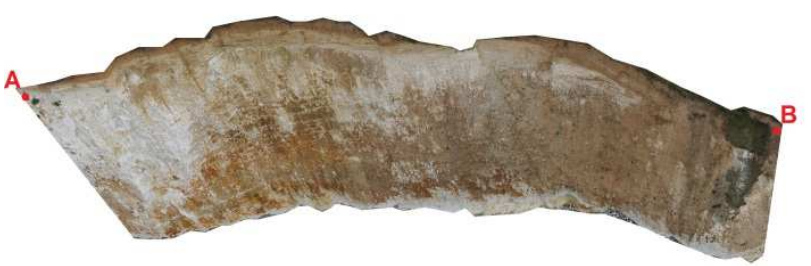

b) Flight 2: $20^{\circ}$ off-nadir

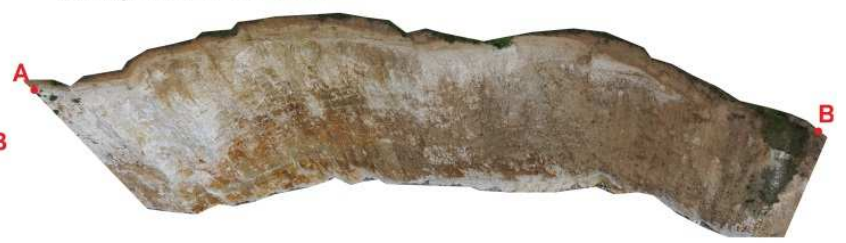

d) Flight 4: $40^{\circ}$ off-nadir

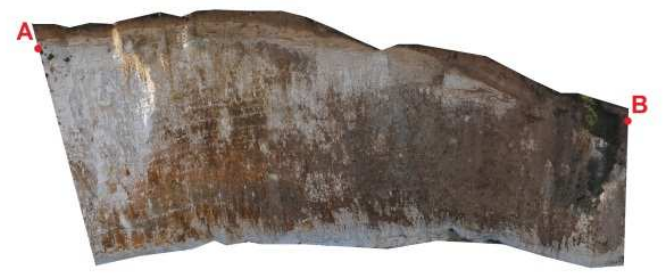

Figure 3 : Comparison of the same portion of the cliff face situated on the eastern part of the studied area depicted on the raw photographs collected with the different acquisition geometries (see the positions of the points $A$ and $B$ marking out the selected cliff portion on Figure 1b): Flight 1 with nadir pointing camera (a), Flight 2 with forward-pointing camera tilted at $\alpha$ $=20^{\circ}$ off-nadir (b), Flight 3 with $\alpha=30^{\circ}$ off-nadir (c) and Flight 4 with $\alpha=40^{\circ}(\mathrm{d})$.

Considering the payload limit, DRELIO cannot be equipped with precise navigation and positioning equipment. Thus, Ground Control Points (GCPs) are required for data processing. The GCPs consist of red discs $30 \mathrm{~cm}$ in diameter distributed on the beach, near the cliff top or the cliff foot (Figure 1d). For this study, 25 circular targets are distributed and positioned using a differential 
post-processed GPS (Topcon HiPer II GNSS receiver). The mean accuracy of the differential GPS (DGPS) survey is $3 \mathrm{~cm}$ horizontally and $4 \mathrm{~cm}$ vertically.

As 2.5-Dimensions Digital Elevation Models are not suited for depicting cliff faces, 3D dense point clouds are used in this study. The 3D point clouds are derived from photographs using a SfMMVS workflow implemented in Agisoft ${ }^{\circledR}$ PhotoScan Professional (version 1.2) [28]. The following steps are involved in 3D dense point cloud reconstruction: i) a camera alignment by bundle adjustment, with detection and matching of tiepoints to compute the camera parameters; and ii) the computation of the position of each tiepoint based on stereophotogrammetric equations. The GCPs are used i) for the self-calibration procedure (i.e. estimating internal parameters of the camera) and ii) for solving the bundle adjustment (i.e. estimating external orientation of the camera), so as to register the 3D reconstruction into a reference coordinates system (here, RGF93 Lambert 93-IGN69, the official reference system in France). The subset of GCPs taken into account for processing varies from one set of photographs (here, one flight) to another (from 11 to 22 GCPs), all GCPs being not visible on every dataset and the GCPs being selected in order to minimize the error estimate computed by PhotoScan ${ }^{\circledR}$.

A Terrestrial Laser Scanner (TLS) survey was acquired simultaneously to serve as reference for assessing the quality of the cliff face reconstruction according to the viewing angle. UAV to TLS point cloud comparisons are performed using CloudCompare ${ }^{\circledR}$ open source software. Many other studies $[7,29-31]$ have used a TLS dataset as the reference for quantitative comparisons, acknowledging that it may also have bias. The TLS survey was carried out using a Riegl ${ }^{\odot}$ VZ-400 TLS, with a vertical and horizontal angular resolution of $0.04^{\circ}$. The high-resolution point cloud is georeferenced indirectly, using 16 reflective targets. The absolute position of these targets is measured by a total station (Trimble ${ }^{\circledR} \mathrm{M} 3$ ) while their relative position in the point cloud is obtained by semi-automatic detection in the TLS point cloud and re-scanning at very fine spatial resolution. The transformation providing the best fit between absolute and relative positions of the targets is computed by a least square algorithm. The residual error of this georeferencing process is of $1.25 \mathrm{~cm}$ for both TLS stations.

\section{Results}

The cliff face reconstructions provided by SfM-photogrammetry from UAV photographs are compared for the different flights. Figure 4 shows the coloured dense point clouds obtained with each viewing angle. As flights with tilting camera have been performed without automatic flight plan, the spatial extent of the reconstructed surface varies from one flight to another. The cliff height is changing in alongshore direction (from a few meters near the dry valley of Petit Ailly to $50 \mathrm{~m}$ height) and certain portions of the upper cliff section have not been captured in the photographs of the tilted-imaging flights due to a sub-optimal UAV trajectory (e.g. on Flight 3 or on the left part of Flight 4 as shown by Figure 4). For a consistent comparison, the UAV datasets are cropped according to the spatial coverage of the TLS dataset, as depicted by the red box on Figure 4. From this point forward, this study is exclusively focused on this comparison zone. 

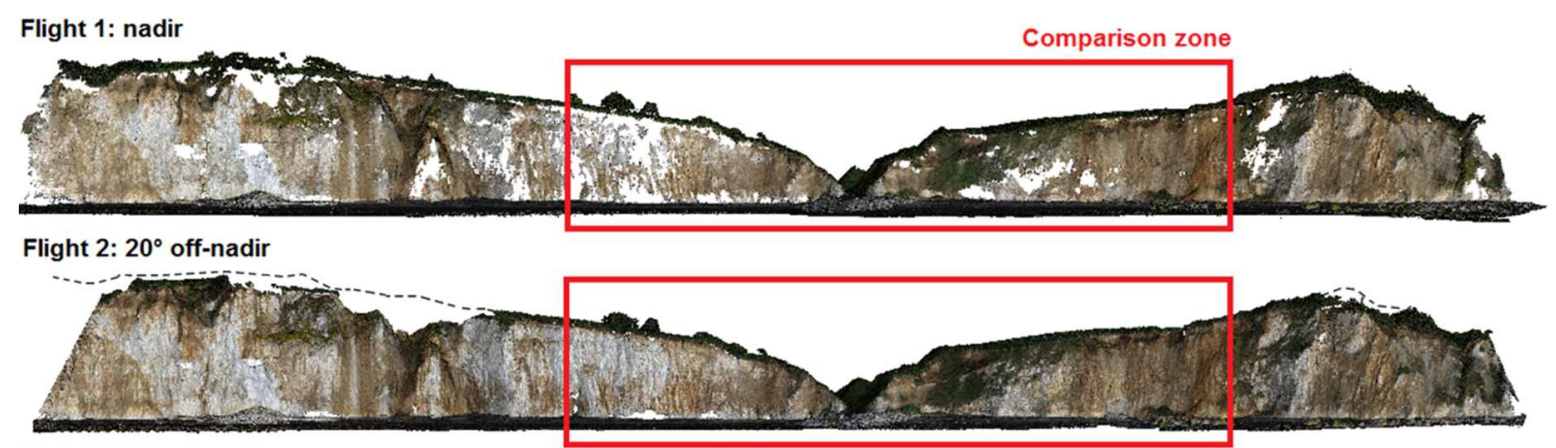

Flight $3: 30^{\circ}$ off-nadir

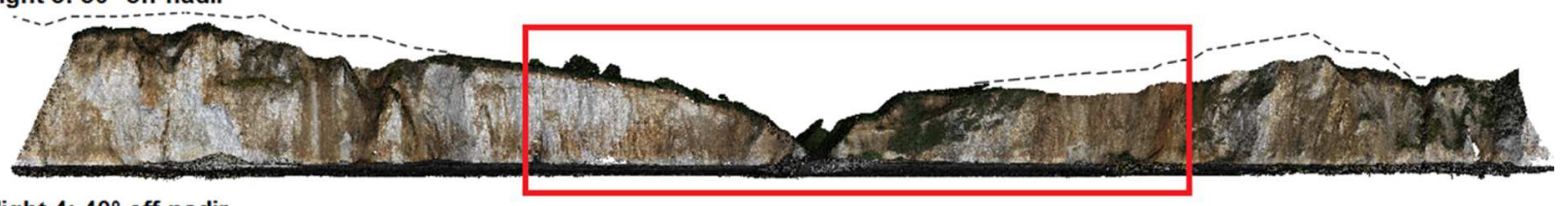

Flight 4: $40^{\circ}$ off-nadir

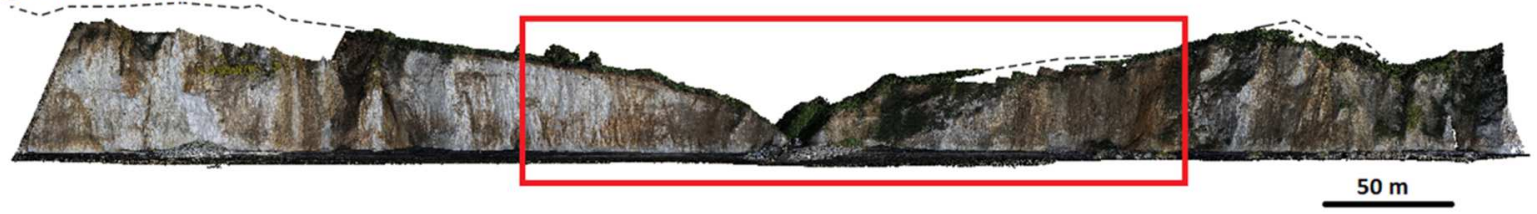

Figure 4 : Comparison of the whole dense point clouds reconstructed by SfM photogrammetry for the different flights. The red box depicts the spatial coverage of the TLS dataset used for the following comparisons. The dashed line indicates the position of the cliff top.

Table 1 compiles some characteristics of the SfM reconstructions for each flight. There are two main reasons for the holes (gaps with no data) within the reconstructed surfaces: i) missing portions of the cliff not captured during the surveys for Flight 3 and Flight 4 due to a sub-optimal UAV trajectory (see Figure 4) or ii) occlusions of some parts of the cliff face due to the low incidence angle of the photographs. This latter effect is particularly noticeable for Flight 1 and to a lesser extent for Flight 2 (see Figure 4). The tiepoint distributions are shown in Figure 5. The number and density of tiepoints vary significantly from one flight to another. As expected, the number of tiepoints is low ( 0.7 tiepoint $/ \mathrm{m}^{2}$ ) for Flight 1 . The dense point cloud resulting from Flight 1 (2 584935 points) counts about half as much points than the dense point clouds of Flights 2, 3 and 4 . When compared to TLS point cloud, the cliff face reconstruction for Flight 1 presents a RMS error of $11.7 \mathrm{~cm}$. Now comparing the 3 tilted-imaging flights, surprisingly the tiepoint density for Flight 2 is more than twice the tiepoint density obtained for Flights 3 and 4 . Nevertheless, for Flights 3 and 4, the tiepoint distribution is rather homogeneous (Figure 5) and the lower number of tiepoints compared to Flight 2 does not affect the cliff face reconstruction. Indeed, the number of points in both resulting dense point clouds is quite similar for these three flights and the precision obtained relatively to TLS point cloud are of the same order of magnitude, with an RMS error of $5.5 \mathrm{~cm}$ for Flight 2, $5.9 \mathrm{~cm}$ for Flight 3 and $4.9 \mathrm{~cm}$ for Flight 4. 
Table 1 : Characteristics of the SfM reconstructions (on the comparison zone depicted in Figure 4) and quantitative comparison to the TLS point cloud.

\begin{tabular}{|c|c|c|c|c|}
\hline & Flight 1 (nadir) & $\begin{array}{c}\text { Flight } 2 \\
\left(20^{\circ} \text { off-nadir) }\right.\end{array}$ & $\begin{array}{c}\text { Flight } 3 \\
\left(30^{\circ} \text { off-nadir) }\right.\end{array}$ & $\begin{array}{c}\text { Flight } 4 \\
\text { (40 off-nadir) }\end{array}$ \\
\hline $\begin{array}{l}\text { Number of } \\
\text { photographs }\end{array}$ & 52 & 92 & 72 & 93 \\
\hline $\begin{array}{l}\text { Reconstructed } \\
\text { surface }\left(\mathrm{m}^{2}\right)\end{array}$ & 5818 & 7000 & 6865 & 7837 \\
\hline $\begin{array}{l}\text { Number of } \\
\text { tiepoints }\end{array}$ & 4029 & 21718 & 10114 & 8560 \\
\hline $\begin{array}{l}\text { Tiepoint density } \\
\left(\mathrm{pts} / \mathrm{m}^{2}\right)\end{array}$ & 0.70 & 3.10 & 1.50 & 1.10 \\
\hline $\begin{array}{l}\mathrm{Nb} \text {. of points in } \\
\text { dense point cloud }\end{array}$ & 2584935 & 5929511 & 5115020 & 5730122 \\
\hline $\begin{array}{l}\text { Point density } \\
\left(\mathrm{pts} / \mathrm{m}^{2}\right)\end{array}$ & 468 & 859 & 747 & 805 \\
\hline \multirow{2}{*}{$\begin{array}{l}\text { Precision relative } \\
\text { to } T L S(\mathrm{~cm})\end{array}$} & 11.7 & 5.5 & 5.9 & 4.9 \\
\hline & $(\sigma=5.0)$ & $(\sigma=2.7)$ & $(\sigma=2.8)$ & $(\sigma=2.7)$ \\
\hline
\end{tabular}

For each row, the coloured data bars depict a relative comparison of the flights.

a) Flight 1: nadir
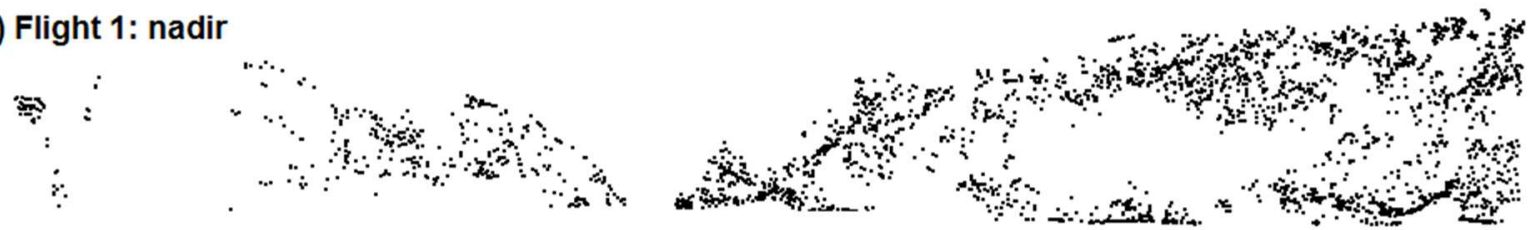

b) Flight $2: 20^{\circ}$ off-nadir
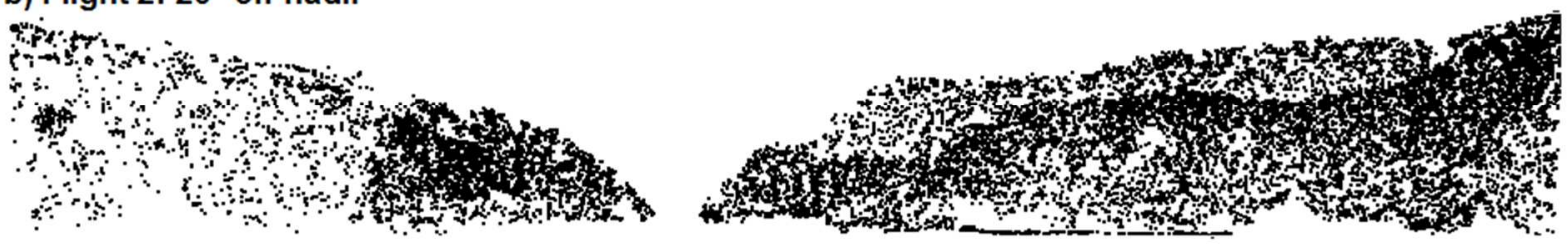

c) Flight $3: 30^{\circ}$ off-nadir

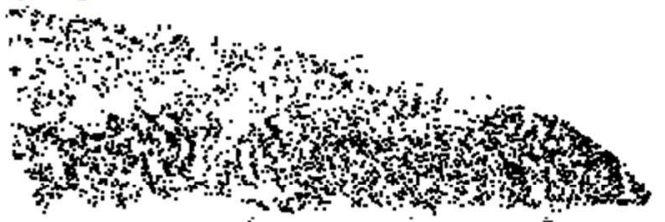

d) Flight 4: $40^{\circ}$ off-nadir
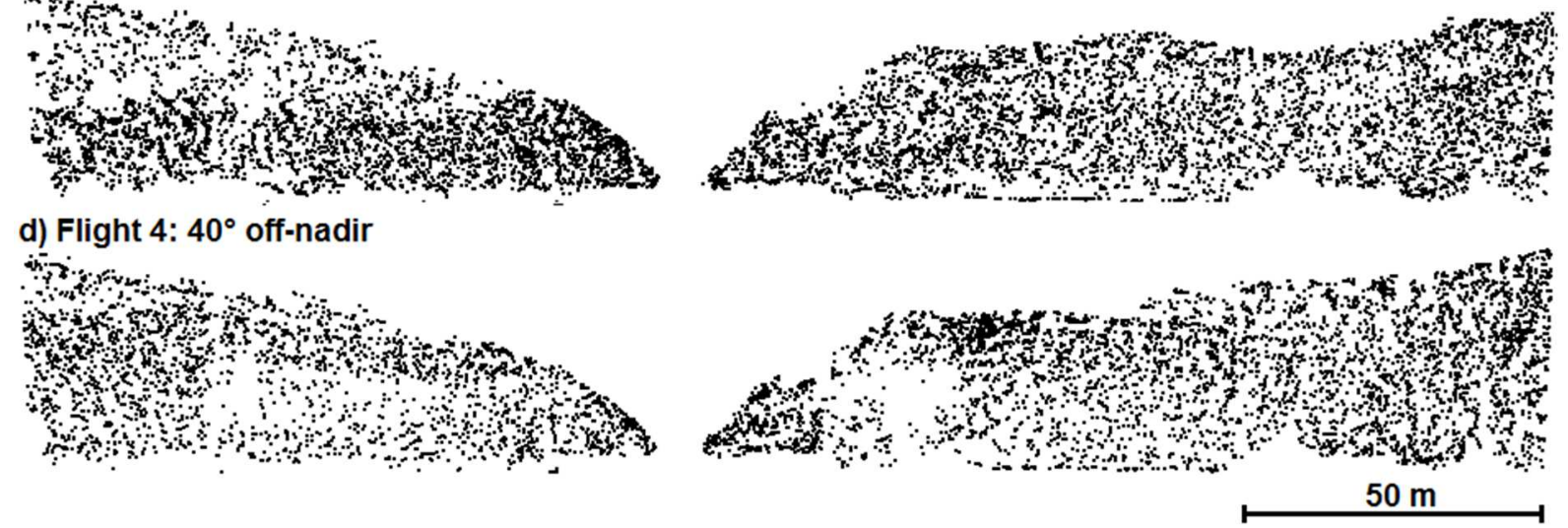

Figure 5: Tiepoint distribution over the comparison zone for the different flights.

Apart from having the lowest point density and missing data within the reconstructed surface, the 3D reconstructions from Flight 1 are also affected by artifacts caused by the low incidence angle of the photographs. As shown in Figure 6, these artifacts consist in variations in point 
density following a pattern of stripes parallel to each other with an approximate "wavelength" (distance from one stripe to the next) varying between 52 and $59 \mathrm{~cm}$.

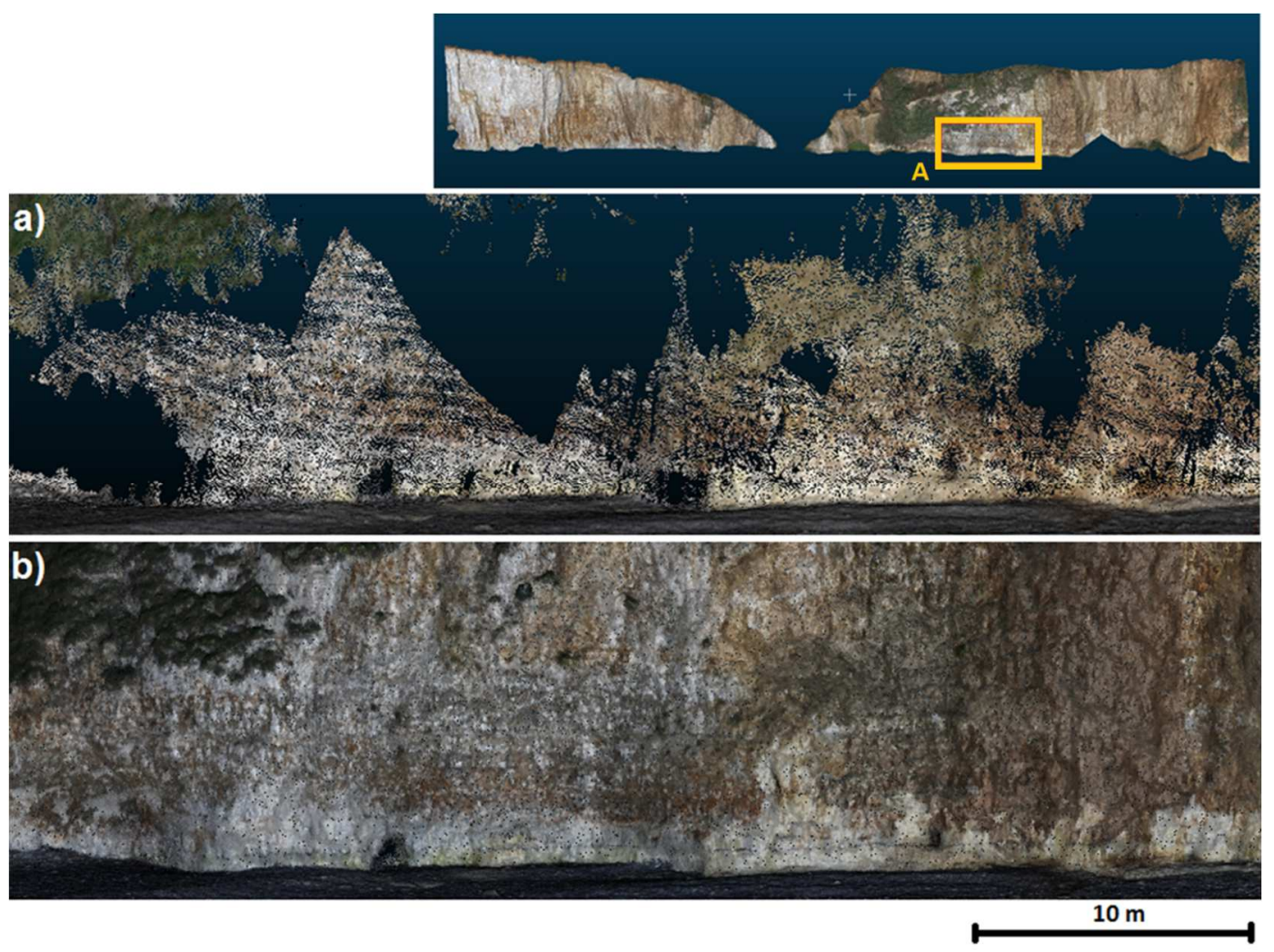

Figure 6: Comparison of the texture restitution zooming on a portion of the cliff face (yellow rectangle of the top figure) a) for Flight 1 with nadir pointing camera versus b) for Flight 4 with forward-pointing camera tilted at $\alpha=40^{\circ}$ off-nadir.

Overall, despite the disparities in tiepoint density, the accuracy of the reconstruction is very similar for Flights 2, 3 and 4. Still, the tilting angle does have an impact in certain specific configurations, such as overhanging surface (i.e. with negative slope) (Figure 7). As expected, for Flight 1, where the mean point cloud density is only 72.6 points $/ \mathrm{m}^{2}$ (Table 2), the cliff surface cannot be reconstructed because of large holes. Some small occlusions are still visible (Figure $7 \mathrm{~b}$ ) on the reconstruction obtained for Flight $2\left(20^{\circ}\right.$ off-nadir), where the point cloud density is about 801 points $/ \mathrm{m}^{2}$. Surprisingly, the occlusions visible on the reconstruction obtained for Flight 3 are very few and very small (Figure 7c) ; yet, with 728 points $/ \mathrm{m}^{2}$, the point cloud density is lower than for Flight 2 . Perhaps the spatial distribution of the points is more homogeneous for Flight 3 , even if they are less numerous. With a tilting angle of $40^{\circ}$, Flight 4 has the best 3D reconstruction (Figure $7 \mathrm{~d}$ ) and the best mean point cloud density (867 points $/ \mathrm{m}^{2}$ - Table 2 ) over the selected overhanging portion of the cliff face. 


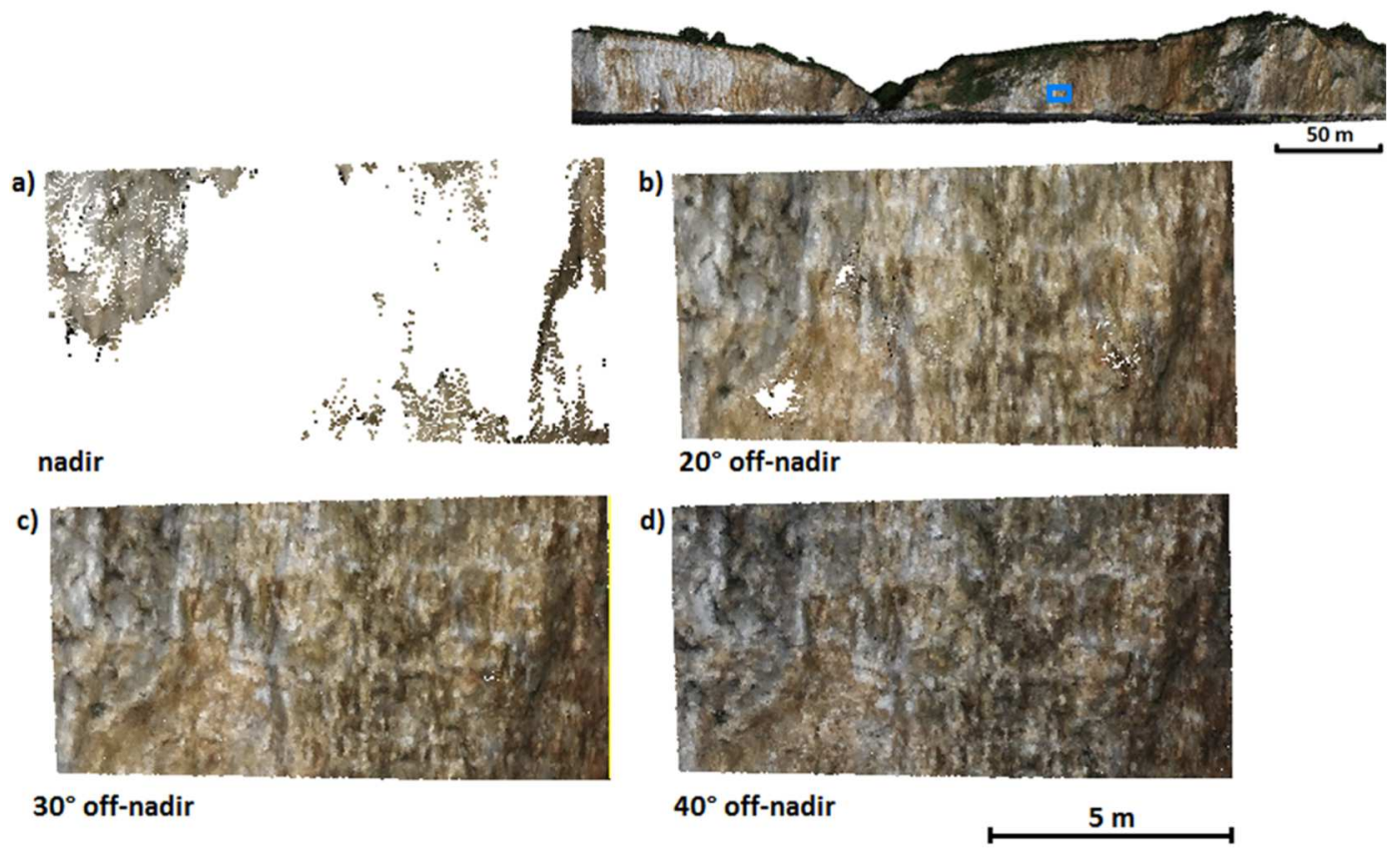

Figure 7: Comparison of the dense point clouds on an overhanging portion of the cliff face (blue rectangle on the top figure) for the different flight configurations.

Table 2: Quantitative comparison of the reconstruction of the overhanging surface depicted in Figure 7.

\begin{tabular}{|c|c|}
\hline & Point cloud density (pts $/ \mathrm{m}^{2}$ ) \\
\hline Flight 1 (nadir) & 72.6 \\
\hline Flight $2\left(20^{\circ}\right)$ & 801.1 \\
\hline Flight $3\left(30^{\circ}\right)$ & 728.0 \\
\hline Flight $4\left(40^{\circ}\right)$ & 867.1 \\
\hline
\end{tabular}

\section{Discussion}

\section{1 - Impact of the cliff slope on the reconstruction}

Up to that point, this article has mostly dealt with "viewing angle" (i.e. the angle between the camera line of sight and the nadir), whereas the key parameter is rather the "angle of incidence" (i.e. the angle between the ray incident on the cliff face and the normal to the cliff face). The angle of incidence mainly depends on the viewing angle and the cliff slope. But the viewing angle is a parameter that can be set before the flight and which remains steady during the survey, whereas the cliff slope is a priori unknown and varies spatially. The impact of the cliff slope is therefore studied empirically, as an environmental constraint.

Between $20^{\circ}$ and $40^{\circ}$ off-nadir, the tilting angle of the camera seems to have a limited impact on the quality of the cliff face reconstruction, except on overhanging areas (Tables 1 and 2). However, the patchy distribution of tiepoints, especially pronounced for Flight 2 (Figure 5), suggests that tiepoint distribution is not only impacted by the imaging angle but also by the cliff slope. To test the effect of cliff slope on the quality of the 3D reconstruction according to the viewing angle, cliff slope has been computed and classified according to four ranges: i) $80^{\circ}-90^{\circ}$, ii) $70^{\circ}-80^{\circ}$, iii) $60^{\circ}-70^{\circ}$ and iv) lower than $60^{\circ}$ (Figure 8). Comparing Figures 5 and 8, some visual correlations can be identified between cliff slope and tiepoint distribution. For instance, zones with tiepoints for Flight 1 correspond to the lowest slopes. Figure 9 summarizes the densities of tiepoints and point clouds 
obtained for the different configurations of viewing angles (Flights 1 to 4) and for each class of cliff slope. As expected, Flight 1 is all the more effective as cliff slopes are low. Tiepoint density is ranges from 0.1 points $/ \mathrm{m}^{2}$ for cliff slope between $80^{\circ}$ and $90^{\circ}$ to 0.9 points $/ \mathrm{m}^{2}$ for cliff slope lower than $60^{\circ}$. For all cliff slope classes, point cloud density is lower for Flight 1 than for other imaging angles. Flight 2 also yields the best results in tiepoint detection for cliff slope lower than $80^{\circ}$. The pronounced maximum in the density of tie points does not occur below $60^{\circ}$ as in Flight 1 but between $60^{\circ}$ and $80^{\circ}$, with up to 3.5 points $/ \mathrm{m}^{2}$ for cliff slope between $70^{\circ}$ and $80^{\circ}$ and 3.4 points $/ \mathrm{m}^{2}$ for cliff slope between $60^{\circ}$ and $70^{\circ}$. For Flights 3 and 4 , tiepoint density does not vary much for the different classes of cliff slope (respectively from 1.1 to 1.3 points $/ \mathrm{m}^{2}$ for Flight 3 and from 0.8 to 1.0 points $/ \mathrm{m}^{2}$ for Flight 4). Surprisingly, tiepoint detection is globally less effective for Flights 3 and 4 than for Flight 2. Nevertheless, except for nadir imaging, the density of the point clouds remains roughly of the same order of magnitude for the different cliff slopes and for the different tilting angles (Flights 2, 3 and 4). Cliff slope has only a limited effect on the quality of the 3D reconstruction for off-nadir viewing angles.

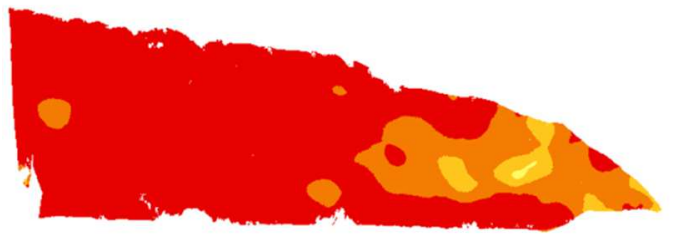

Cliff slope (percentage of the cliff face):
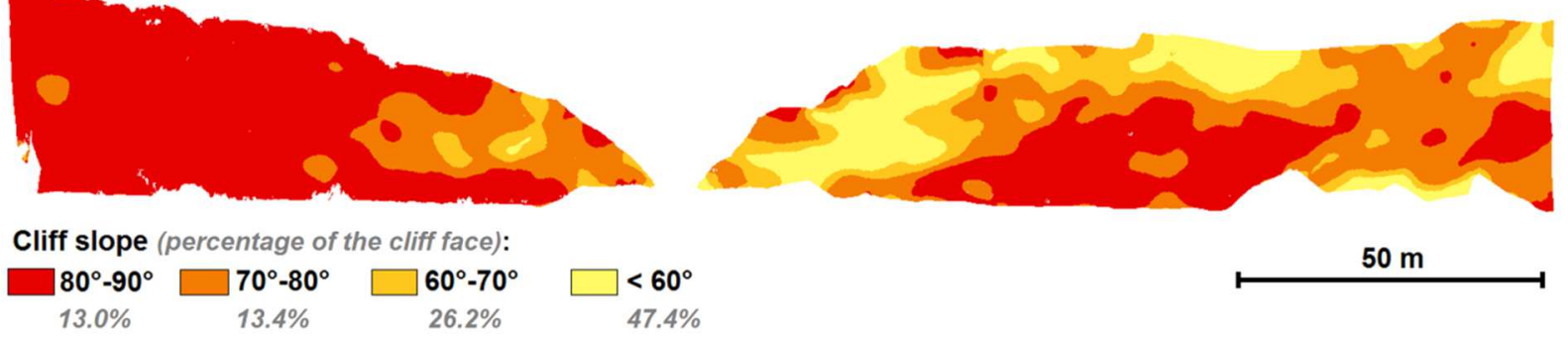

Figure 8: Classification of the cliff slope.
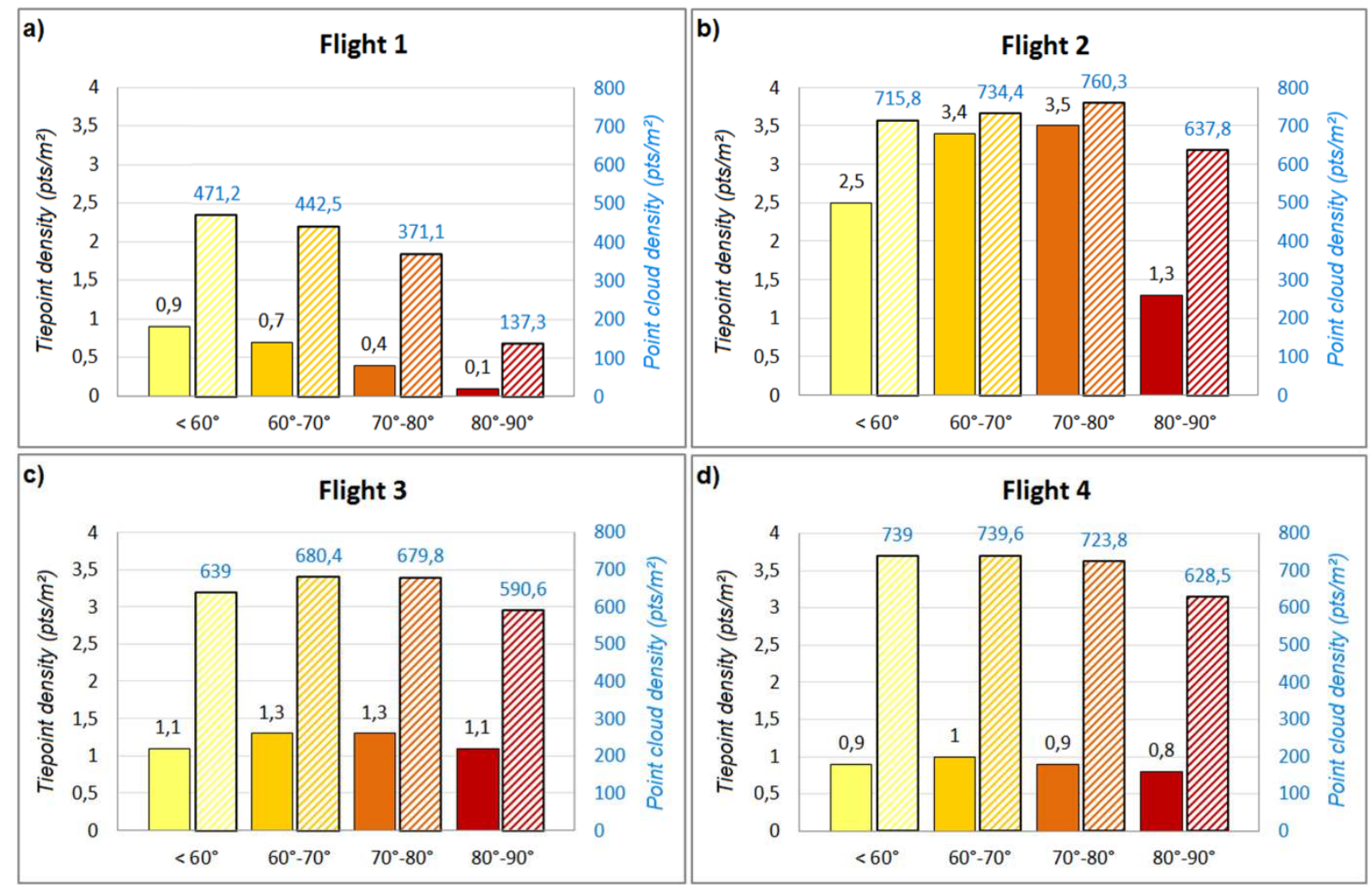

d)

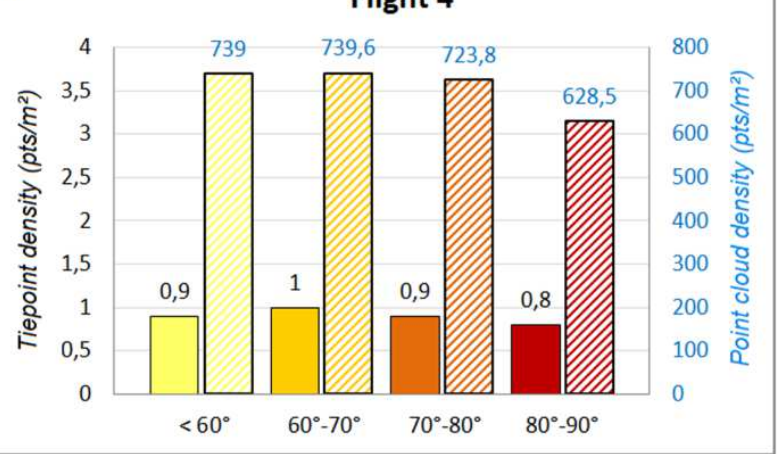


Figure 9: Influence of the cliff slope on the quality of reconstruction for the various viewing angles.

\section{2 - Factors impacting tiepoints detection}

Considering the noticeable differences between Flights 2, 3 and 4, this comparison suggests that cliff slope and camera viewing angles are not the only parameters having an effect on the cliff face reconstruction process. Point cloud reconstruction is mainly affected by the effectiveness of tiepoint detection. Three main factors have been identified as likely to have an influence on tiepoint detection:

i) Firstly, the overlapping of the photographs on the cliff face impacts tiepoint detection. Image overlap (Figure 10) depends on the spatial coverage of the photographs and therefore of the imaging angle in relation to the cliff slope. For instance, for Flight 1 (Figure 10a), the viewing angle is nearly parallel to the cliff face, so the footprint of the photographs on the cliff face is very limited. But overlapping also depends on the flight characteristics, like the speed of the UAV and the distance to the cliff, which affect the ground coverage of images. To quantify the degree of overlapping of the photographs for a survey, an "effective overlap" parameter (i.e. the mean number of matched photographs capturing each tiepoint in the sparse point cloud) is computed for the comparison zone and for the whole survey (Table 3). The effective overlap on the cliff face increases with the off-nadir angle, from 3.19 for Flight 1 to 11.54 for Flight 4.

ii) Another factor likely to affect the tiepoint detection is the resolution of the photographs on the cliff face. The spatial resolution is mainly influenced by the distance between the UAV and the cliff face and by the angle of incidence. The smaller features or texture variations are no longer captured when the drone flies further away from the cliff face and the image resolution decreases, so they cannot be detected as tiepoints anymore. As the flights are not performed in "automatic mode" and because of variations in cliff heights, the UAV-cliff face distance varies during a flight. A mean distance between the UAV and the cliff face summit is computed (Table 3). The UAV-cliff face distance ranges from $46 \mathrm{~m}$ to $76 \mathrm{~m}$ for tilted-imaging flights and is $72 \mathrm{~m}$ for Flight 1.

iii) Finally, variations in cliff face illumination due to cloud cover variability can also have a significant impact on tiepoint detection. Due to the north-facing orientation of the cliff face, it is when the cloud cover decreases that the cliff face appears darker because it is then in its own shadow. Low light levels tend to make tiepoints detection more difficult on the photographs. As an example, on the cliff portion depicted in Figure 3, the luminosity on the cliff face is of $53.7 \%$ for Flight 1, 48.8\% for Flight 2, $49.8 \%$ for Flight 3 and only $40.0 \%$ for Flight 4 (Table 3 ). It can be assumed that the tiepoints detection for Flight 4 would have been more effective with higher luminosity on the cliff face. 


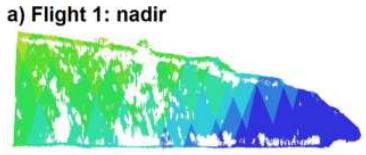

c) Flight 3: $30^{\circ}$ off-nadir

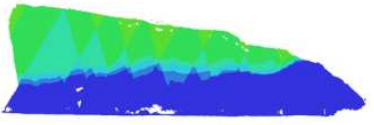

Number of overlapping images

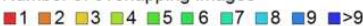
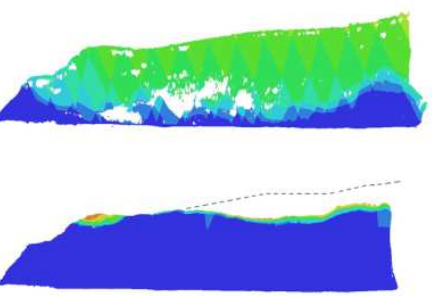

b) Flight 2: $20^{\circ}$ off-nadir

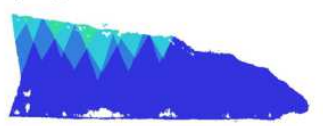

d) Flight 4: $40^{\circ}$ off-nadir

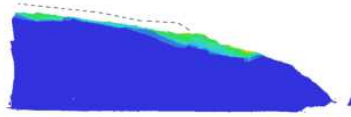

Figure 10: Configuration of the image overlap on the cliff face in the comparison zone.

Table 3: Comparison of other acquisition parameters likely to affect the tiepoint detection. Luminosity has been measured on the cliff portion shown in Figure 3 (between sections $A$ and B). Effective overlap is computed on the cliff face over the comparison zone and for the whole survey using raw images (with top of the cliff and beach). Mean distance is computed for the comparison zone between the UAV position and the cliff face summit.

\begin{tabular}{|c|c|c|c|}
\hline & Effective overlap & $\begin{array}{c}\text { Mean distance of the UAV } \\
\text { to the cliff face summit }\end{array}$ & $\begin{array}{c}\text { Luminosity (measured on } \\
\text { the cliff portion in Figure 3) }\end{array}$ \\
\hline $\begin{array}{c}\text { Flight 1 } \\
\text { (nadir) }\end{array}$ & $\begin{array}{c}\text { comparison zone: } 3.19 \\
\text { whole survey: } 7.95\end{array}$ & $72 \mathrm{~m}$ & $53.7 \%$ \\
\hline $\begin{array}{c}\text { Flight 2 } \\
\text { (20\% off-nadir) }\end{array}$ & $\begin{array}{c}\text { comparison zone: } 5.96 \\
\text { whole survey: } 7.01\end{array}$ & $46 \mathrm{~m}$ & $48.8 \%$ \\
\hline $\begin{array}{c}\text { Flight 3 } \\
\text { (30\% } \text { off-nadir) }\end{array}$ & $\begin{array}{c}\text { comparison zone: } 6.58 \\
\text { whole survey: } 11.23\end{array}$ & $64 \mathrm{~m}$ & $49.8 \%$ \\
\hline $\begin{array}{c}\text { Flight 4 } \\
\text { (40\% off-nadir) }\end{array}$ & $\begin{array}{c}\text { comparison zone: } 11.54 \\
\text { whole survey: } 13.52\end{array}$ & $76 \mathrm{~m}$ & $40.0 \%$ \\
\hline
\end{tabular}

We propose that tiepoint detection is less effective for Flight 3 than for Flight 2 because of the larger mean distance of the UAV to the cliff face summit and the lower image overlap on the eastern portion (Figure 10c), and that tiepoint detection is less effective for Flight 4 than for Flight 2 because of the larger mean distance of the UAV to the cliff face summit and the lower luminosity on the cliff face, the latter being detrimental to tiepoint detection.

In addition, other parameters, inherent to the study area, can influence the process of cliff face reconstruction, and particularly tiepoint detection. Indeed, the image matching is based on local invariant feature detection [32], such as SIFT descriptor [33], Harris [34] or SURF descriptors [35]. Nevertheless, the algorithm actually used in PhotoScan ${ }^{\circledR}$ is not publicly known [36]. These descriptors are scale and rotation invariant and partially intensity and contrast change invariant [32]. As a consequence, the surface roughness (likely to create shadows), the colors of the rock face and the resulting color contrast, the presence of vegetation (depending itself on the cliff slope and on the substratum), etc. can also impact on tiepoint detection. Furthermore, depending on the viewing angle, the SfM reconstruction process can be more or less impacted by geometrical distortions [7, 37]. Considering the number and diversity of involved parameters, it is difficult to further assess their individual impact on the SFM process of cliff face reconstruction.

\section{Guidelines for flight parameterization}

With the development of UAVs with retractable landing system and 3-axis gimbal, it will soon be possible to perform flights with an across-track pointing camera using the automatic mode of the autopilot. With such UAVs, flights can to be planned so as to find a good trade-off between viewing 
angle, limitation of occlusion effects, spatial resolution on the cliff face and flight safety (flying too close to the cliff face exposes to local wind effects as well as loss of GPS signal).

In this perspective, we propose some guidelines and abacuses to assist in UAV flight parameterization for alongshore cliff face monitoring. The following calculations are done for various camera configurations: $35 \mathrm{~mm}$ or $24 \mathrm{~mm}$ focal length, a CCD sensor of $35.9 \mathrm{~mm} \times 24 \mathrm{~mm}$ and 6 Mpix, 12 Mpix, 20 Mpix or 32 Mpix images. As we consider alongshore surveys, we choose to capture the whole cliff height in a single photograph centered at mid-cliff height. The UAV will follow a cliff-parallel trajectory (Figure 11a), where the distance D of the UAV to the cliff face and the UAV flight height $\mathrm{H}$, which are the convenient variables for programing waypoints in the UAV autopilot, will be selected to optimize the viewing angle and more generally the point cloud reconstruction process. These variables $\mathrm{D}$ and $\mathrm{H}$ are linked via the tilting angle $\alpha$ of the camera, following the equation (1):

$$
D=H \times \tan \alpha-\frac{H_{\text {Cliff }}}{2} \tan \left(\frac{\pi}{2}-\alpha\right)
$$

with:

D: Horizontal distance between the UAV and the cliff face

$\alpha$ : camera pointing angle

$\mathrm{H}_{\text {cliff: }}$ height of the cliff

Given the choice of a single flyover, the angle $\alpha$ and the cliff height $H_{\text {cliff }}$ define an axis oblique to the cliff that we call R-axis (Figure 11a). The range along the R-axis (i.e., the position of the drone), and thus the selected $\mathrm{D}-\mathrm{H}$ pair, is mainly chosen according to the expected image resolution. As previously mentioned, the distance to the cliff face can also be impacted by safety constraints, and the flight height can be limited by flight regulations for example. The abacus in Figure $11 \mathrm{~b}$ presents possible D-H pairs for various configurations of camera viewing angle and cliff height. Figure $11 \mathrm{c}$ shows the mean spatial resolution obtained for various configurations of the viewing angles and cameras as a function of D (UAV-cliff distance), following the equation (2):

$$
r_{\text {cliff }}=\frac{D \times s_{p i x}}{f \times \sin ^{2}(\alpha)}
$$

with:

$r_{\text {cliff: }}$ image resolution on the cliff face

D: Horizontal distance between the UAV and the cliff face

Spix: physical size of the pixel on the CCD sensor

$f:$ focal length

$\alpha$ : camera pointing angle

It has to be noticed that Equation 2 and Figure 11 only provide the mean image resolution, whereas in practice the spatial resolution decreases from the cliff foot to cliff top. Knowing the required image resolution, the focal length and the image quality, Figure $11 \mathrm{c}$ helps to find the appropriate camera angle and distance from the cliff face and Figure $11 \mathrm{~b}$ enables to find the corresponding UAV flight height. 

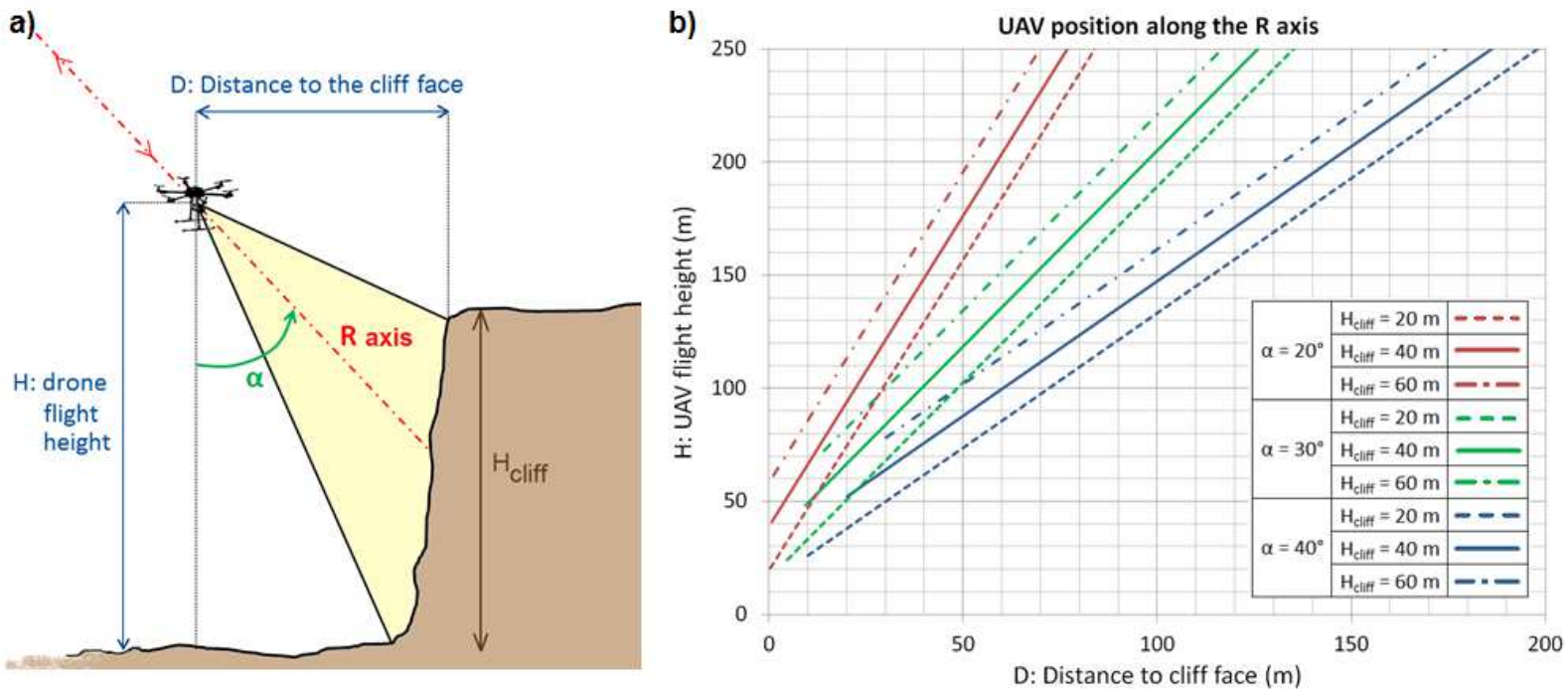

c) Image resolution on the cliff face

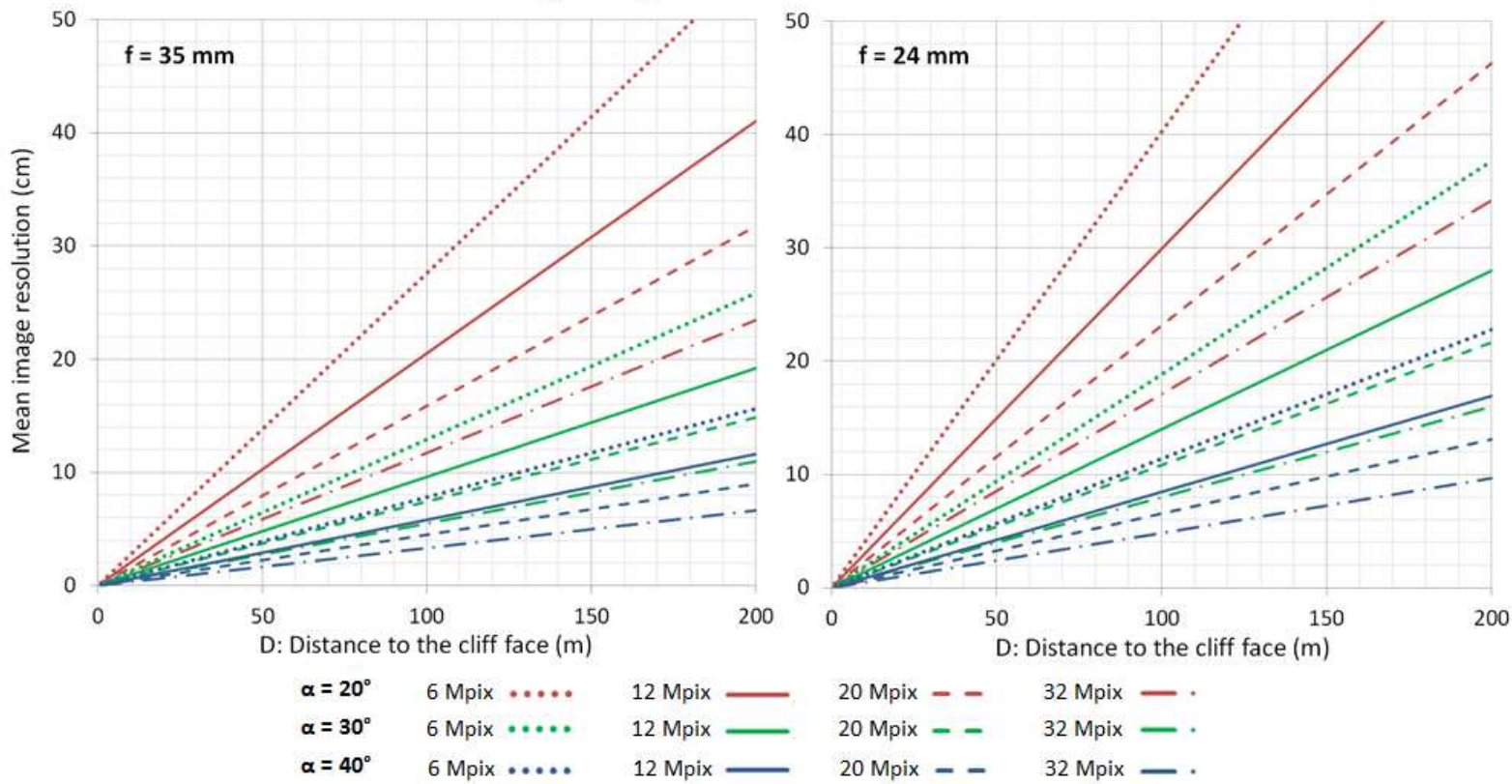

Figure 11: Schematic configuration diagram of UAV alongshore survey of cliff face (a) and abacuses to find the best trade-off between distance to the cliff face and flight height $(b)$ and between distance to the cliff face and image resolution (c) for various configurations of camera viewing angles $\left(\alpha=20^{\circ}, 30^{\circ}\right.$ and $\left.40^{\circ}\right)$, focal length and image quality (6 Mpix, $12 \mathrm{Mpix}, 20$ mpix, 32 Mpix).

\section{Conclusion}

In this study, we assessed the effectiveness of various imaging angles to perform UAV longshore surveys of a cliff face. Our results show that surveys with nadir pointing camera are nearly irrelevant, particularly for sub-vertical cliffs. In addition, the comparisons show that $20^{\circ}, 30^{\circ}$ and $40^{\circ}$ off-nadir imaging angles provide satisfying results in terms of accuracy and texture restitution, higher tilting angles being more relevant for sub-vertical or overhanging parts of the cliff.

This study also highlights that imaging angle and cliff slope are not the only parameters impacting the SfM-photogrammetric process of cliff face reconstruction. The effectiveness of tiepoint detection also appears to be a key parameter. The tests presented in this article indicate that tiepoint detection is influenced by the photographs overlap, the distance between the UAV and the cliff face 
(and thus, the spatial resolution of the photographs) and the illumination of the cliff face. It is difficult to identify a priori which parameters have most impact on cliff face reconstruction and the extent to which they can affect diachronic comparisons of dense point clouds for the purpose of monitoring coastal erosion. Future work could be focused on the identification of other proxies than precision to estimate the reliability of dense point clouds obtained by SfM-photogrammetry.

\section{Acknowledgement}

The authors acknowledge financial support provided by the TOSCA project EROFALITT from the CNES (the French space agency). This work is also part of the "Service National d'Observation" DYNALIT, via the research infrastructure ILICO.

\section{Bibliography}

[1] Lim, M., Rosser, N.J., Petley, D.N., Keen, M., 2011. Quantifying the Controls and Influence of Tide and Wave Impacts on Coastal Rock Cliff Erosion. Journal of Coastal Research 27, 46-56. https://doi.org/10.2112/JCOASTRES-D-09-00061.1

[2] Letortu, P., Costa, S., Maquaire, O., Delacourt, C., Augereau, E., Davidson, R., Suanez, S., Nabucet, J., 2015. Retreat rates, modalities and agents responsible for erosion along the coastal chalk cliffs of Upper Normandy: The contribution of terrestrial laser scanning. Geomorphology 245, 3-14. https://doi.org/10.1016/j.geomorph.2015.05.007

[3] Mancini, F., Castagnetti, C., Rossi, P., Dubbini, M., Fazio, N., Perrotti, M., Lollino, P., 2017. An Integrated Procedure to Assess the Stability of Coastal Rocky Cliffs: From UAV Close-Range Photogrammetry to Geomechanical Finite Element Modeling. Remote Sensing 9, 1235. https://doi.org/10.3390/rs9121235

[4] Young, A.P., Olsen, M.J., Driscoll, N., Flick, R.E., Gutierrez, R., Guza, R.T., Johnstone, E., Kuester, F., 2010. Comparison of Airborne and Terrestrial Lidar Estimates of Seacliff Erosion in Southern California. Photogrammetric Engineering \& Remote Sensing 76, 421-427. https://doi.org/10.14358/PERS.76.4.421

[5] James, M.R., Robson, S., 2012. Straightforward reconstruction of 3D surfaces and topography with a camera: Accuracy and geoscience application. J. Geophys. Res. Earth Surf. 117. https://doi.org/10.1029/2011JF002289

[6] Agüera-Vega, F., Carvajal-Ramírez, F., Martínez-Carricondo, P., Sánchez-Hermosilla López, J., Mesas-Carrascosa, F.J., García-Ferrer, A., Pérez-Porras, F.J., 2018. Reconstruction of extreme topography from UAV structure from motion photogrammetry. Measurement 121, 127-138. https://doi.org/10.1016/j.measurement.2018.02.062

[7] Letortu, P., Jaud, M., Grandjean, P., Ammann, J., Costa, S., Maquaire, O., Davidson, R., Le Dantec, N., Delacourt, C., 2018. Examining high-resolution survey methods for monitoring cliff erosion at an operational scale. GIScience \& Remote Sensing 55, 457-476. https://doi.org/10.1080/15481603.2017.1408931 
[8 Westoby, M.J., Lim, M., Hogg, M., Pound, M.J., Dunlop, L., Woodward, J., 2018. Cost-effective erosion monitoring of coastal cliffs. Coast. Eng. 138, 152-164. https://doi.org/10.1016/j.coastaleng.2018.04.008

[9] Lim, M., Petley, D.N., Rosser, N.J., Allison, R.J., Long, A.J., Pybus, D., 2005. Combined digital photogrammetry and time-of-flight laser scanning for monitoring cliff evolution. Photogramm. Rec. 20, 109-129. https://doi.org/10.1111/j.1477-9730.2005.00315.x

[10] Rosser, N.J., Petley, D.N., Lim, M., Dunning, S.A., Allison, R.J., 2005. Terrestrial laser scanning for monitoring the process of hard rock coastal cliff erosion. Q. J. Eng. Geol. Hydrogeol. 38, 363375. https://doi.org/10.1144/1470-9236/05-008

[11] Rosser, N.J., Brain, M.J., Petley, D.N., Lim, M., Norman, E.C., 2013. Coastline retreat via progressive failure of rocky coastal cliffs. Geology 41, 939-942. https://doi.org/10.1130/G34371.1

[12] Kuhn, D., Prüfer, S., 2014. Coastal cliff monitoring and analysis of mass wasting processes with the application of terrestrial laser scanning: A case study of Rügen, Germany. Geomorphology 213, 153-165. https://doi.org/10.1016/j.geomorph.2014.01.005

[13] Michoud, C., Carrea, D., Costa, S., Derron, M.H., Jaboyedoff, M., Delacourt, C., Maquaire, O., Letortu, P., Davidson, R., 2015. Landslide detection and monitoring capability of boat-based mobile laser scanning along Dieppe coastal cliffs, Normandy. Landslides 12, 403-418. https://doi.org/10.1007/s10346-014-0542-5

[14] Roca, D., Armesto, J., Lagüela, S., Díaz-Vilariño, L., 2014. Lidar-equipped uav for building information modelling. ISPRS - International Archives of the Photogrammetry, Remote Sensing and Spatial Information Sciences XL-5, 523-527. https://doi.org/10.5194/isprsarchives-XL-5523-2014

[15] Firpo, G., Salvini, R., Francioni, M., Ranjith, P.G., 2011. Use of Digital Terrestrial Photogrammetry in rocky slope stability analysis by Distinct Elements Numerical Methods. International Journal of Rock Mechanics and Mining Sciences 48, 1045-1054. https://doi.org/10.1016/j.jirmms.2011.07.007

[16] Dewez, T.J.B., Leroux, J., Morelli, S., 2016. Cliff Collapse Hazard from repeated multicopter UAV acquisitions: return on experience. ISPRS - International Archives of the Photogrammetry, Remote Sensing and Spatial Information Sciences XLI-B5, 805-811. https://doi.org/10.5194/isprsarchives-XLI-B5-805-2016

[17] Cawood, A.J., Bond, C.E., Howell, J.A., Butler, R.W.H., Totake, Y., 2017. LiDAR, UAV or compassclinometer? Accuracy, coverage and the effects on structural models. Journal of Structural Geology 98, 67-82. https://doi.org/10.1016/j.jsg.2017.04.004

[18] Rossi, P., Mancini, F., Dubbini, M., Mazzone, F., Capra, A., 2017. Combining nadir and oblique UAV imagery to reconstruct quarry topography: methodology and feasibility analysis. European Journal of Remote Sensing 50, 211-221. https://doi.org/10.1080/22797254.2017.1313097 
[19] Fritz, A., Kattenborn, T., Koch, B., 2013. UAV-based photogrammetric point clouds - Tree stem mapping in open stands in comparison to Terrestrial Laser scanner point clouds. ISPRS International Archives of the Photogrammetry, Remote Sensing and Spatial Information Sciences XL-1/W2, 141-146. https://doi.org/10.5194/isprsarchives-XL-1-W2-141-2013

[20] Grenzdörffer, G.J., Guretzki, M., Friedlander, I., 2008. Photogrammetric image acquisition and image analysis of oblique imagery. The Photogrammetric Record 23, 372-386.

https://doi.org/10.1111/j.1477-9730.2008.00499.x

[21] Aicardi, I., Chiabrando, F., Grasso, N., Lingua, A.M., Noardo, F., Spanò, A., 2016. UAV photogrammetry with obliques images: first analysis on data acquisition and processing. ISPRS - International Archives of the Photogrammetry, Remote Sensing and Spatial Information Sciences XLI-B1, 835-842. https://doi.org/10.5194/isprs-archives-XLI-B1-835-2016

[22] Pomerol, B., Bailey, H.W., Monciardini, C., Mortimore, R.N., 1987. Lithostratigraphy and biostratigraphy of the Lewes and Seaford chalks: A link across the Anglo-Paris Basin at the Turonian-Senonian boundary. Cretac. Res. 8, 289-304.

[23] Mortimore, R.N., Stone, K.J., Lawrence, J., Duperret, A., 2004. Chalk physical properties and cliff instability, in: Coastal Chalk Cliff Instability, Geological Society Engineering Geology Special Publication. pp. 75-88.

[24] Bignot, G., 1962. Etude sédimentologique et micropaléontologique de l'Eocène du Cap d'Ailly (près de Dieppe-Seine-Maritime). Paris.

[25] Letortu, P., Costa, S., Bensaid, A., Cador, J.-M., Quénol, H., 2014. Vitesses et modalités de recul des falaises crayeuses de Haute-Normandie (France): méthodologie et variabilité du recul. Geomorphol. Relief Process. Environ. 20, 133-144. https://doi.org/10.4000/geomorphologie.10872

[26] Letortu P., Costa S., Maquaire O., Davidson R., submitted. 7-years monitoring of coastal chalk cliff erosion in Normandy (France) by terrestrial laser scanning: main results. Geomorphology.

[27] Varnes, D.J., 1978. Slope movement types and processes, in: Landslides: Analysis and Control. Washington, pp. 11-33.

[28] Jaud, M., Passot, S., Le Bivic, R., Delacourt, C., Grandjean, P., Le Dantec, N., 2016. Assessing the Accuracy of High Resolution Digital Surface Models Computed by PhotoScan ${ }^{\circledR}$ and MicMac ${ }^{\circledR}$ in Sub-Optimal Survey Conditions. Remote Sensing 8, 465. https://doi.org/10.3390/rs8060465

[29] Westoby, M.J., Brasington, J., Glasser, N.F., Hambrey, M.J., Reynolds, J.M., 2012. 'Structurefrom-Motion' photogrammetry: A low-cost, effective tool for geoscience applications. Geomorphology 179, 300-314. https://doi.org/10.1016/j.geomorph.2012.08.021

[30] Eltner, A., Baumgart, P., Maas, H. G., and D. Faust. 2015. "Multi-temporal UAV data for automatic measurement of rill and interrill erosion on loess soil." Earth Surface Processes and Landforms 40: 741-755.

[31] Smith, M. W., Carrivick, J., and D. Quincey. 2016. "Structure from motion photogrammetry in physical geography." Progress in physical geography 40: 247-275 
[32] Lou L., Liu Y., Sheng M., Han J., Doonan J.H. 2014. A Cost-Effective Automatic 3D Reconstruction Pipeline for Plants Using Multi-view Images, in: Mistry M., Leonardis A., Witkowski M., Melhuish C. (eds) Advances in Autonomous Robotics Systems. TAROS 2014. Lecture Notes in Computer Science, vol 8717. Springer, Cham. DOI: 10.1007/978-3-319-10401-0_20

[33] Lowe, D.G. 2004. "Distinctive image features from scale-invariant keypoints". International Journal of Computer Vision 60: 91-110

[34] Stephens, M.C.H. 1988. A combined corner and edge detector, in: Proc. of Fourth Alvey Vision Conference. Manchester, pp. 5-10.

[35] Bay, H., Ess, A., Tuytelaars, T., Gool, L.V. 2008. "Speeded-up robust features (surf)". Computer Vision and Image Understing 110: 346-359

[36] Verhoeven, G., Karel, W., Štuhec, S., Doneus, M., Trinks, I., Pfeifer, N. 2015. “Mind your grey tone - Examining the influence of decolourization methods on interest point extraction and matching for architectural image-based modelling". ISPRS - International Archives of the Photogrammetry, Remote Sensing and Spatial Information Sciences XL-5/W4: 307-314. https://doi.org/10.5194/isprsarchives-XL-5-W4-307-2015

[37] James, M.R., Robson, S., 2014. Mitigating systematic error in topographic models derived from UAV and ground-based image networks: MITIGATING SYSTEMATIC ERROR IN TOPOGRAPHIC MODELS. Earth Surface Processes and Landforms 39, 1413-1420. https://doi.org/10.1002/esp.3609 